\title{
Update on drowning
}

\author{
J Matthew, ${ }^{1}$ BSc, MB ChB, DipPEC (SA), FAWM; C Robertson, ${ }^{2}$ MB ChB, FCEM; \\ R Hofmeyr, ${ }^{3} \mathrm{MB}$ ChB, DipPEC (SA), MMed (Anaes), FCA(SA), FAWM \\ ${ }^{1}$ Department of Emergency Medicine, Faculty of Health Sciences, University of KwaZulu-Natal, Durban; and Lifesaving South Africa, Durban, South Africa
${ }^{2}$ National Sea Rescue Institute, Cape Town, South Africa \\ ${ }^{3}$ Department of Anaesthesia and Perioperative Medicine, Faculty of Health Sciences, University of Cape Town; and WildMedix, Cape Town, South Africa
}

Corresponding author: J Matthew (rapid.sequence@yahoo.com)

Drowning is defined as the process of experiencing respiratory impairment from either submersion or immersion in liquid. Drowning morbidity and mortality are an under-recognised public health burden in southern Africa. Continuous concerted efforts are underway to improve awareness among recreational water users, but the prevention and management of drowning remain difficult to achieve owing to poor reporting and limited resources. Priorities for both prehospital and emergency department management of drowning victims include ensuring airway patency, adequate ventilation, supplemental oxygenation and rewarming for a pulsatile patient, and cardiopulmonary resuscitation with rewarming for a pulseless patient.

S Afr Med J 2017;107(7):562-565. DOI:10.7196/SAMJ.2017.v107i7.12609

\section{Scenario}

An 18-year-old matriculant goes to the beach with friends to celebrate his school results. The ensuing boisterous party includes consumption of alcohol. As dusk falls, he goes for a swim with his girlfriend. She is soon seen waving frantically to their friends back on the beach. He has disappeared below the water surface. Their friends swim out, and after 10 minutes they manage to find him, and bring him to shore. They immediately start cardiopulmonary resuscitation (CPR), while calling for help.

\section{Background}

Despite being essential to life, water, which comprises $>60 \%$ of our body mass and covers $>75 \%$ of the surface our planet, continues to be an occupational and recreational threat to humans. Drowning among young adults in South Africa (SA) is unfortunately especially common. Poor swimming ability due to historical lack of access to facilities, concomitant alcohol use and easy access to rivers, lakes and the ocean are all contributing factors. This is compounded by relatively limited resources to respond to drowning incidents across wide, unpatrolled areas, resulting in a growing burden of disease affecting the younger population groups in SA. Recognition of a drowning event is also a problem, as not every drowning victim will indicate their need for assistance (Fig. 1). This review examines the evidence and recommendations on drowning from an African perspective, and brings the health fraternity one step closer to developing guidelines for our country.

\section{Definition}

Drowning is defined as the process of experiencing respiratory impairment from either submersion or immersion in liquid. ${ }^{[1]}$ Drowning outcomes are classified as either drowning with mortality, drowning with morbidity, or drowning without morbidity ${ }^{[1]}$ Other older terms (such as wet, dry or near drowning) have been deemed unhelpful, and have been abandoned.

\section{Epidemiology}

Drowning epidemiology varies dramatically worldwide, but is notably more severe in low- to middle-income countries. US data report

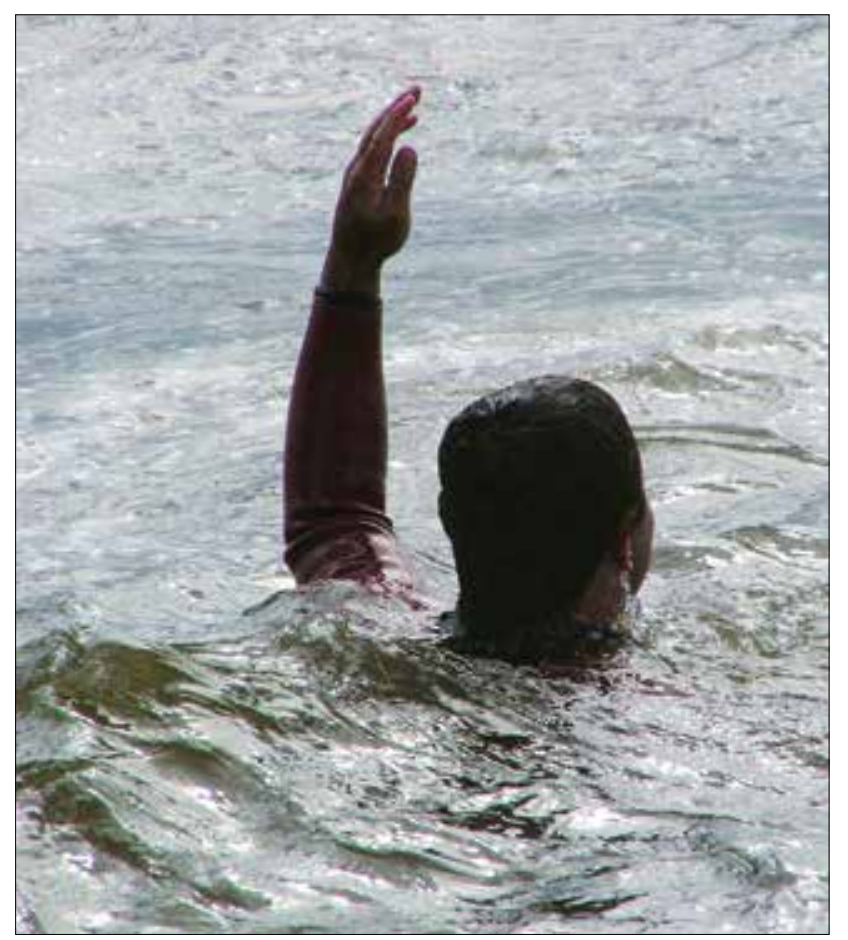

Fig. 1. Contrary to common belief, drowning victims are frequently unable to signal for help, and will often go unnoticed.

$\sim 4000$ drowning deaths, 8000 hospitalisations and 31000 emergency department (ED) visits per year for children $<19$ years old. ${ }^{[2]}$ Regrettably, there are no consistent published data for SA, but preliminary information from Lifesaving South Africa (LSA) reveals similar trends in age demographics, although true numbers are largely unknown. ${ }^{[3]}$ Extrapolation from forensic pathology data in the Western Cape provides an estimation of 4/100 000 fatal drownings per year, which is similar to the World Health Organization's estimations for low-income countries in Africa. Despite only an estimated 1 in 4 cases being reported, Africa has the highest rate of drowning in the world. ${ }^{[4]}$ 


\section{Recent guidelines development}

Recently updated guidelines for the prevention, prehospital and ED management of drowning have been published by the Wilderness Medical Society (WMS). ${ }^{[5]}$ However, application of international guidelines within a resource-limited setting must be carefully weighed. In SA, the WMS guidelines are undergoing review by the Wilderness and Expedition Medicine Society of Southern Africa to ensure relevance in the SA context. Nonetheless, they offer evidencebased practice standards, of which the key features and other notable research in the field are being integrated with the Western Cape Drowning Prevention Strategy under development by LSA, the National Sea Rescue Institute (NSRI) of SA, Western Cape Provincial Disaster Management, and the SA Medical Research Council. The ultimate objective is to extend this to developing a national strategy.

\section{Drowning prevention}

Drowning is associated with generally poor outcomes, and therefore the initial focus should always be on a pervasive and reiterated prevention strategy. Anyone involved in recreational or professional water-related activities should have baseline medical screening to rule out medical diseases that predispose them for having sudden loss of competence in water. In particular, seizure disorders and prolonged QT syndrome must be sought in children considered at risk. ${ }^{[6,7]}$

A concerted effort must be made to educate children and teenagers on survival swimming (flotation), which should be integrated into life skills programmes at school. ${ }^{[8]}$ Personal flotation devices should be encouraged, irrespective of swimming ability, especially in young children. Adult supervision - particularly in the home environment - is paramount to prevent drowning. ${ }^{[9]}$ Swimming pool covers and barriers to prevent access to pools by small children are essential, but unfortunately remain unregulated in SA.

In poorer rural communities where drowning is common in freshwater environments (dams, rivers, ponds, buckets, baths, ditches, sewage latrines or wells), prevention is particularly challenging. Alcohol use before and during swimming must be discouraged. ${ }^{[7]}$ Swimming in areas where there are lifeguards on patrol must also be encouraged or enforced.

\section{Prehospital management}

The rescue of drowning victims requires specific skills, physical abilities and certified training. Rescues attempted by people who do not fulfil these criteria place the potential rescuers at risk. ${ }^{[5]}$ Individuals without appropriate training should try to reach out to victims, while ensuring that they have secured themselves to a fixed point. If this is unsuccessful, throwing a buoyant device to the victim is an alternative. Depending on the scenario, this may even be the first response while help is sought. If available, a watercraft may be used to reach the victim. None of these efforts should place potential rescuers at risk

Trained rescuers perform at their level of experience, skill and physical abilities, using the equipment they have available. In-water resuscitation is difficult, and should only be attempted when the victim cannot be removed from the water quickly and safely, and only by trained rescuers. There is little evidence to suggest that anything more than ventilation is beneficial for a victim of drowning who is still in the water. ${ }^{[5]}$

Once out of the water, and as soon as possible after addressing immediate threats to life, the victim should be actively and passively warmed, depending on available means. Once it is established that the patient has a pulse, the immediate priorities for resuscitation are airway management, oxygenation and ventilation. ${ }^{[10]}$ For a pulseless person, CPR should commence with chest compressions, with attention to airway patency, ventilations and supplemental oxygen provision. The Heimlich manoeuvre is not indicated where water with particulate matter remains the cause of airway obstruction. ${ }^{[11]} \mathrm{CPR}$ should follow standard basic life-support principles. ${ }^{[12]}$ Defibrillation may not be effective in severely hypothermic patients, where submersion times were prolonged. The focus here would be effective chest compressions with rewarming. ${ }^{[13,14]}$

The incidence of associated cervical spine injuries in drowning incidents is $<5 \%$, and is usually associated with diving from a height. ${ }^{[5]}$ Spinal protection is therefore not a concern in drowning unless there is a significant mechanism for cervical spine injury, significant distracting injuries, a focal neurological deficit, anatomical disruption, abnormalities in the cervical spine causing concern or an altered mental status. ${ }^{[15]}$

Unless there is an immediate threat to life or active CPR, there should not be delays in transferring the drowning patient to hospital for assessment and further management. Vascular access is not usually indicated, and undue time should not be spent in the field to gain access.

\section{Emergency department management}

The initial priorities for a drowning victim are the same, whether in the prehospital or ED setting. If the patient remains pulseless, the focus is on effective CPR with rewarming, following advanced cardiovascular life-support guidelines. ${ }^{[12]}$ If the patient has a pulse, rewarming and monitoring should occur while attention is paid to airway patency, oxygenation to a targeted peripheral arterial saturation of at least $95 \%$, and adequate ventilation. ${ }^{[16]}$ If mechanical ventilation is used, as indicated, a lung protective strategy should be used with positive end-expiratory pressure (PEEP) and $\mathrm{FiO}_{2}$ to maintain adequate $\mathrm{PaO}_{2}$. Non-invasive ventilation can be considered if there are no contraindications in hypoxic patients with mild to moderate respiratory symptoms. The literature regarding therapeutic hypothermia management for drowning victims is unclear. ${ }^{[17]}$ There may be a role for patients with return of spontaneous circulation after cardiac arrest following drowning.

Unless otherwise indicated, an initial chest radiograph has no value, as it does not correlate with outcomes or other investigations. An initial arterial blood gas measurement may be useful in determining the titration of oxygenation and the need for ventilation. ${ }^{[18]}$ Despite early animal evidence demonstrating pathophysiological differences in salt- and freshwater drowning, this has not been clearly distinguished in humans. ${ }^{[19]}$ Electrolyte abnormalities and changes in osmolarity only occur when $>11-22 \mathrm{~mL} / \mathrm{kg}$ of water are aspirated, while studies show that in human drowning $\sim 3-4 \mathrm{~mL} / \mathrm{kg}$ are aspirated. ${ }^{[18]}$ Therefore, the role of routine electrolyte testing is questionable.

Alternative diagnoses should be considered if the patient continues to have an altered mental status despite optimal medical therapy. Comorbid illness or injury may have been the precipitating factor for submersion or immersion.

Early empiric antibiotic use in ED management is not indicated. ${ }^{[20]}$ It is difficult to differentiate between the stress response of drowning and true infectious aetiology based on early imaging and laboratory testing, and even bedside diagnostics may be insensitive. Antibiotics may be considered with persistently high fever and increased sputum production. Procalcitonin testing may be beneficial to assist in the clinical decision to commence antibiotic therapy. Routine steroid use is similarly not indicated. ${ }^{[20]}$ 
Table 1. Classification of drowning patients based on clinical findings on initial presentation and associated mortality

\begin{tabular}{llll}
\hline Grade & Respiratory findings & Cardiovascular findings & Mortality, \% \\
\hline 0 & Normal auscultation and no cough & Radial pulses present & 0 \\
1 & Normal auscultation with mild cough & Radial pulses present & 0 \\
2 & Rales, small amount of foam in mouth & Radial pulses present & 0.6 \\
3 & Acute pulmonary oedema & Radial pulses present & 5.2 \\
4 & Acute pulmonary oedema & Hypotension & 19 \\
5 & Respiratory arrest & Hypotension & 44 \\
Adapted from Schmidt t al. ${ }^{[5]}$ & Cardiopulmonary arrest & Pulselessness & 93
\end{tabular}

Table 2. Prediction of mortality in paediatric drowning: the Orlowski score

\begin{tabular}{ll}
\hline Prognostic factor & Orlowski score \\
\hline Age $<3$ years & 1 point awarded for each unfavourable prognostic factor \\
Estimated maximum submersion time $>5$ minutes & Score of $\leq 2=90 \%$ chance of recovery \\
No attempts at resuscitation for $>10$ minutes after rescue & Score of $\geq 3=5 \%$ chance of recovery \\
Comatose on arrival in emergency department & \\
Arterial blood gas $\mathrm{pH} \leq 7.10$ & \\
Adapted from Anderson et al. ${ }^{[2]}$ &
\end{tabular}

\section{Disposition planning}

Drowning victims seen in the ED can be observed for $4-6$ hours and discharged if they present with a mild or absent cough, no abnormal lung sounds or altered mental status, and improve or do not deteriorate during the observation period. ${ }^{[5]}$ Criteria for admission include severe cough, abnormal lung sounds, frothy sputum or foamy material in the airway, hypotension (systolic blood pressure $<90 \mathrm{mmHg}$ or mean arterial pressure $<60 \mathrm{mmHg}$ ) and altered mental status. ${ }^{[5]}$

Several prognostic tools have been suggested to assist with predicting outcomes from drowning. Submersion time has an exponentially negative relationship with survival. Hypoxia remains the main predictor of outcome. ${ }^{[21]}$ If the patient survives to the ED, mortality can still be $\geq 93 \%$, depending on the initial presentation. ${ }^{[5]}$ Table 1 describes the initial clinical findings and the associated mortality rates. Hypotension alone immediately predicts a mortality of $\geq 19 \%$.

The Orlowski score (Table 2) is used in paediatric drowning scenarios to determine prognosis. ${ }^{[22]}$

When patients present to the ED in cardiac arrest with active resuscitation efforts, a decision must be made on whether to continue with resuscitation. This is often difficult and emotionally charged for ED staff. Poor prognostic indicators from drowning studies are submersion times $>30$ minutes, with water temperatures $>6^{\circ} \mathrm{C}$; submersion times $>90$ minutes, with water temperatures $<6^{\circ} \mathrm{C}$; and at least 25 minutes of continuous high-quality CPR without return of spontaneous circulation. ${ }^{[5,23]}$ In well-resourced settings, bridging to extracorporeal membrane oxygenation may be appropriate, particularly in drowning associated with significant hypothermia.

\section{Scenario resolution}

The drowned celebrating matriculant received immediate and highquality bystander CPR from his school friends, who had learnt first aid during their life skills classes. A rapid prehospital response provided advanced cardiovascular life support and swift air transportation to a nearby hospital capable of dealing with drowning victims, where he was rapidly warmed in the ED and admitted to the intensive care unit for 2 weeks. With ideal management, he recovered steadily, and could commence university studies after the holidays, with an intact neurological state.

\section{Conclusion}

Drowning prevention and management is a complex interplay between personal and family responsibility, first-responder awareness, prehospital provider training, effective evidence-based ED management and critical care support with appropriate prognostication.

It also involves social and government advocacy for preventive interventions that begin at home and are integrated into school programmes. Guidance is required from expert bodies such as LSA and the NSRI, and the collaboration of a multidisciplinary framework of stakeholders to ensure that this problem is addressed nationally and perennially.

\section{Learning points}

Drowning is defined as the process of experiencing respiratory impairment from either submersion or immersion in liquid.

Priorities for both prehospital and ED management of the drowning victim include ensuring airway patency, adequate ventilation, supplemental oxygenation and rewarming for a pulsatile patient, and CPR with rewarming for a pulseless patient.

The initial priorities for a drowning victim are the same, whether it is in the prehospital or ED setting.

1. Van Beeck EF, Branche CM, Szpilman D, Modell JH, Bierens JJLM. A new definition of drowning Towards documentation and prevention of a global public health problem. Bull World Health Organ 2005;83(11):853-856. https://doi.org//S0042-96862005001100015

2. Hwang V, Shofer FS, Durbin DR, Baren JM. Prevalence of traumatic injuries in drowning and near Hwang V, Shofer FS, Durbin DR, Baren JM. Prevalence of traumatic injuries in drowning and near
drowning in children and adolescents. Arch Pediatr Adolesc Med 2003;157(1):50-53. https://doi. drowning in children and ados

3. Donson H, van Niekerk A. Unintentional drowning in urban South Africa: A retrospective Donson H, van Niekerk A. Unintentional drowning in urban South Africa: A retrospective
investigation, 2001 - 2005. Int J Inj Contr Saf Promot 2013;20(3):218-226. https://doi.org/10.1080/1 7457300.2012 .686041 
4. World Health Organization. Facts about injuries: Drowning. In: Injuries and Violence Prevention. Geneva: WHO, 2014.

5. Schmidt AC, Sempsrott JR, Hawkins SC, Arastu AS, Cushing TA, Auerbach PS. Wilderness Medical Society Practice Guidelines for the Prevention and Treatment of Drowning. Wilderness Environ Med 2016;27(2):236-251. https://doi.org/10.1016/j.wem.2015.12.019

6. Bell GS, Gaitatzis A, Bell CL, Johnson AL, Sander JW. Drowning in people with epilepsy: How great is the risk? Neurology 2008;71(8):578-582. https://doi.org/10.1212/01.wnl.0000323813.36193.4d

7. Papadodima SA, Athanaselis SA, Skliros E, Spiliopoulou CA. Forensic investigation of submersion deaths. Int J Clin Pract 2010;64(1):75-83. https://doi.org/10.1111/j.1742-1241.2008.01890.x

8. Weiss J, Gardner HG, Baum CR, et al. Policy statement - prevention of drowning. Pediatrics 2010;126(1):178-185. https://doi.org/10.1542/peds.2010-1264

9. Franklin RC, Scarr JP, Pearn JH. Reducing drowning deaths: The continued challenge of immersion fatalities in Australia. Med J Aust 2010;192(3):123-126.

10. Szpilman D, Bierens JJLM, Handley AJ, Orlowski JP. Drowning. N Engl J Med 2012;366(22):21022110. https://doi.org/10.1056/NEJMra1013317

11. Layon AJ, Modell JH. Drowning: Update 2009. Anesthesiology 2009;110(6):1390-1401. https://doi. org/10.1097/ALN.0b013e3181a4c3b8

12. Soar J, Perkins GD, Abbas G, et al. European Resuscitation Council Guidelines for Resuscitation 2010 Section 8. Cardiac arrest in special circumstances: Electrolyte abnormalities, poisoning, drowning accidental hypothermia, hyperthermia, asthma, anaphylaxis, cardiac surgery, trauma, pregnancy, electrocution. Resuscitation 2010;81(10):1400-1433. https://doi.org/10.1016/j.resuscitation.2010.08.015
13. Harries M. Near drowning. BMJ 2003;327(7427):1336-1338. https://doi.org/10.1136/bmj.327.7427.1336 14. Salomez F, Vincent JL. Drowning: A review of epidemiology, pathophysiology, treatment and prevention. Resuscitation 2004;63(3):261-268. https://doi.org/10.1016/j.resuscitation.2004.06.007

15. Watson RS, Cummings P, Quan L, Bratton S, Weiss NS. Cervical spine injuries among submersion victims. J Trauma 2001;51(4):658-662. https://doi.org/10.1097/00005373-200110000-00006

16. Wang TL. Management of victims with submersion injury. Ann Disaster Med 2004;2(Suppl 2):S89-S96. 17. Choi SP, Youn CS, Park KN, et al. Therapeutic hypothermia in adult cardiac arrest because of drowning Choi SP, Youn CS, Park KN, et al. Therapeutic hypothermia in adult cardiac arrest because of drow
Acta Anaesthesiol Scand 2012;56(1):116-123. https://doi.org/10.1111/j.1399-6576.2011.02562.x

18. Topiian AA, Berg RA, Biernes JJLM, et al. Brain resuscitation in the drowning victim. Neurocrit Care 2012;17(3):441-467. https://doi.org/10.1007/s12028-012-9747-4
20

19. Cushing TA, Hawkins SC, Sempsrott J Schoene RB. Submersion injuries and drowning In: Auerbach PS. Wilderness Medicine. Philadelphia: Elsevier, 2012: 1494-1513.

20. Gregorakos L, Markou N, Psalida V, et al. Near-drowning: Clinical course of lung injury in adults. Lung Gregorakos L, Markou N, Psalida V, et al. Near-drowning: Clinic

21. Ballesteros MA, Gutierrez-Cuadra M, Munoz P, Minambres E. Prognostic factors and outcome after drowning in an adult population. Acta Anaesthesiol Scand 2009;53(7):935-940. https://doi after drowning in an adult population.

22. Anderson KC, Roy TM, Danzl DF. Submersion incidents: A review of 39 cases and development of the submersion outcome score. J Wilderness Med 1991;2(1):27-36. https://doi.org/10.1580/0953-9859-2.1.27 23. Tipton MJ, Golden FS. A proposed decision-making guide for the search, rescue and resuscitation of submersion (head under) victims based on expert opinion. Resuscitation 2011;82(7):819-824. https:// doi.org/10.1016/j.resuscitation.2011.02.021 